\title{
Estimating the economic damages from the Penglai 19-3 oil spill to the Yantai fisheries in the Bohai Sea of northeast China
}

\author{
Guangchen Pan ${ }^{\mathrm{a}}$, Shengyao Qiu ${ }^{\mathrm{a}}$, Xin Liu ${ }^{\mathrm{b}, *}$, Xiaoke $\mathrm{Hu}^{\mathrm{b}}$ \\ a The School of Ocean, Yantai University, Yantai 264005, China \\ ${ }^{\mathrm{b}}$ Yantai Institute of Coastal Zone Research, Chinese Academy of Sciences, Yantai 264003, China
}

\section{A R T I C L E I N F O}

\section{Article history:}

Received 11 February 2015

Received in revised form

15 July 2015

Accepted 4 August 2015

Available online 31 August 2015

Keywords:

Economic damages

Fisheries

Oil spill

\begin{abstract}
A B S T R A C T
The Penglai 19-3 oil spill was one of the worst pollution incidents to occur along the Chinese coastline in terms of both the size of the spill and the area polluted with 840 square kilometers of previously clean coastal waters significantly degraded. The current study estimated economic damages from the spill in two economic sectors, the Yantai fishery and the Yantai mariculture business. Estimates revealed that the ecological damage to fisheries and mariculture affected local crustacean species, shellfish, algae, sea cucumbers and sea urchins much more seriously than the adult fish, partly because fish are very mobile and partly because of the submarine nature of the PL19-3 spill. Toxic oil floating on the sea surface created less of a threat to fish, when comparing them with benthos and algae. Therefore, the economic losses were mainly caused by a reduction in the productivity of crustaceans, shellfish, algae, sea cucumbers and sea urchins, totaling as much as ${ }^{1} \mathrm{CNY} 1239.5$ million for 63,044 $\mathrm{t}$ in weight. Together with the loss in the fishing sector (i.e., CNY16.85 million), the total economic losses were about CNY12.56 billion.
\end{abstract}

(c) 2015 Elsevier Ltd. All rights reserved.

\section{Introduction}

The Bohai Sea of northeastern China is a C shaped semi-closed water body with an averaged depth of $18 \mathrm{~m}$. Both the maritime ecosystem and economy of the Bohai Sea are very important; the Bohai Sea is highly vulnerable to any pollution from oil spills [1]. On 4 June 2011, oil was detected on the surface of coastal waters near platform B of the Penglai 19-3 (i.e., PL19-3) offshore drilling field at $38^{\circ} 21^{\prime} 48.055^{\prime \prime} \mathrm{N}, 120^{\circ} 5^{\prime} 21.966^{\prime \prime} \mathrm{E}$. A report issued by Conoco-Phillips China, Inc. (COPC), the oil drilling company involved in the incident, a mixture of drilling mud containing $115 \mathrm{~m}^{3}$ of oil and $416 \mathrm{~m}^{3}$ of mineral oil was released into the Chinese Bohai Sea [2].

Specifically, the PL19-3 spill site lies very close to the vulnerable coastal zone of the northern part of Yantai, a Chinese prefecture-level city with very important coastal fishery activities, consisting of 10 coastal counties (Fig. 1). This study analyzed the status of more than 10 maritime species that had potentially been locally affected by the oil spill including prawn, crab, oyster, abalone, mussel, scallop, clam, sinonovacula, kelp, sea cucumber, sea urchin, Penaeus chinensis (Chinese white shrimp), Portunus trituberculatus (gazami crab) and Rhopilema esculentum (flame

\footnotetext{
* Corresponding author. Fax: +865352109000.

E-mail address: xliu@yic.ac.cn (X. Liu).

${ }^{1}$ USD $1.0=$ CNY 6.2 in June 2015.
}

jellyfish). These species mainly contributed to two local economic activities in the Yantai region: mariculture and fisheries. The local fishery relies heavily on a stock enhancement program (stocking program).

The so-called stock enhancement program involves the release of hatchery-reared juveniles into the wild to replenish the depleted natural supply of juveniles and to stimulate the local fishery by increasing the number of fish available for harvest [3]. Of course, stock enhancement is not a new concept. Hatchery-based stocking has been a crucial technique used in an attempt to restore marine biological resources during the latter part of the 20th and early decades of the 21st centuries [4]. As reported in a fisheries technical paper produced by the United Nations Food and Agriculture Organization (FAO), Japan had a leading position in the development of marine stock enhancement [5-7]. From the late 1900s, Japan, the United States, Russia, Norway, Spain, Britain, Germany, and other countries have conducted stocking programs and treated these programs as an important part of the future development of resource conservation and ecological restoration efforts. Stocking programs have accelerated worldwide and the scale of these programs has also grown in some countries [8]. China has conducted a stocking program in the Chinese Bohai Sea for several decades with $P$. chinensis, $P$. trituberculatus, and $R$. esculentum as three major species being stocked through this type of program. 


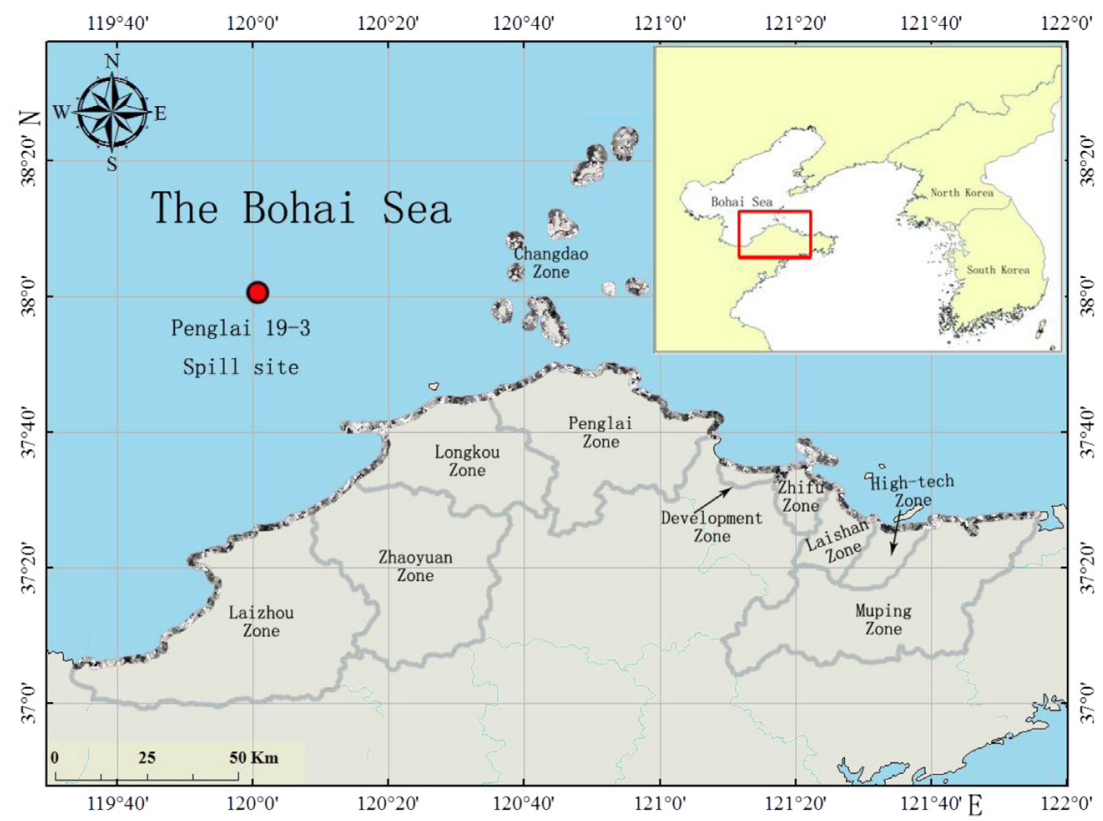

Fig. 1. The analyzed coastal area of the Yantai coastal area consists of 10 sub-zones, among which the Changdao zone includes a group of islands.

The PL19-3 oil spill affected not only in Yantai coastal areas, but effects were also observed in other provinces including Hebei and Liaoning. These provinces also experienced fishery losses caused by this spill and those were expected to be as high as that in the Yantai area. Initially, 29 fishermen from the Hebei Province sued COPC to demand compensation of CNY241.61 million for their economic losses related to mariculture at the very beginning of the accident [9], followed by many additional cases of reported damaged to mariculture in those provinces. By the end of the August 2011, government employees were still finding and collecting patches of oil in Hebei and Liaoning provinces [10]. Because of the constraints on data available in the above two provinces, this paper focuses on a short-term economic assessment of damages from the PL19-3 oil spill in the local Yantai mariculture and fishery sectors of the economy.

In this paper, Section 2 presents a short review of effects and assessment of oil spills in recent literature; Section 3 deals with the data and methodology used in the present study; Section 4 presents an estimation of economic damages in both the mariculture and fishery sectors; Sections 5 and 6 present a discussion and summarizes the major findings of the paper, respectively.

\section{Effects and assessment of oil other spills}

Oil behaves in a variety of ways in marine ecosystems, including causing toxic, smothering, and sometimes lethal effects [11]. The Xinhua News agency reported that rotting crustaceans and dead algae could be seen along the coast after the Penglai 19-3 oil spill [12]. An abundance of published literature has demonstrated the significant environmental and economic effects caused by accidental oil spills. For example in 1996, the Sea Empress oil spill released 72,360 $t$ of oil that spread off the coast of the UK and resulted in a total economic loss of USD 63.147 million [13]. In 1999, the Erika oil spill caused USD 549.1 million of ecological damage and USD 234.3 million of material damage in France [1416]. The Prestige oil spill occurred off the Galician coast of Spain in 2002 , and resulted in a loss of $66 \%$ of species richness in some areas, with detectable effects on sediment quality and on offshore fish and crustacean fisheries [17-20]. Based on Liu and Wirtz [21], the overall cost for the Prestige was nearly EUR2250 million including the commercial and environmental losses, cleanup costs, research costs and other expenditures. Aside from a total of 17,061 birds killed in this accident, as many as 33 dead mammals were collected on the beaches of Galicia until December 2002, consisting of 15 dolphins, seven turtles, three whales, and eight individuals of other species [22]. The Hebei Spirit Oil Spill incident in 2007 in Korean waters caused severe damage to $350 \mathrm{~km}^{2}$ of fish nurseries located in South Chungcheong and North Jeolla provinces [23]; this spill damaged $375 \mathrm{~km}$ of coastline, including 100 offshore islands and 15 beaches. Approximately 43,000 fishing households suffered losses, with over $97 \%$ of those located in South Chungcheong Province [14].The Dalian, China, oil spill on July 16,2010 , polluted a sea area of $430 \mathrm{~km}^{2}$ with $1500 \mathrm{t}$ of oil. The total economic losses were estimated to be CNY4480 million including losses to the fishery, the sea food, salt and tourism industries, and costs of cleanup [24].

\section{Methods}

\subsection{The investigation area}

The PL19-3 oil spill had major effects on the coastal area of Yantai because these coastal areas were very close to the spill site. For example, the spill site was only $60 \mathrm{~km}$ from Changdao Island, one of zones affiliated to the Yantai area. The XinMin Weekly reported that local fishermen living on Changdao Island observed oil slicks [25].

Yantai, located along the Shandong Peninsula and connected to the Bohai Sea, serves as an important seafood production area for China. Its crooked coastline, nutrient-rich water, appropriate temperature, and convenient access to transportation facilities are very beneficial to the development of mariculture and the stocking program in the Yantai region. The history of mariculture started very early, with the cultivation of kelp in 1978. Several mariculture methods have recently been developed, including lagoon, raft and cage culture techniques, indoor factory farming, and bottom sowing cultivation in the shallow sea. Ten regions of developing mariculture along the northern coast of the Yantai include the Changdao Island Zone, the zones of Laishan, Laizhou, Muping, 
A

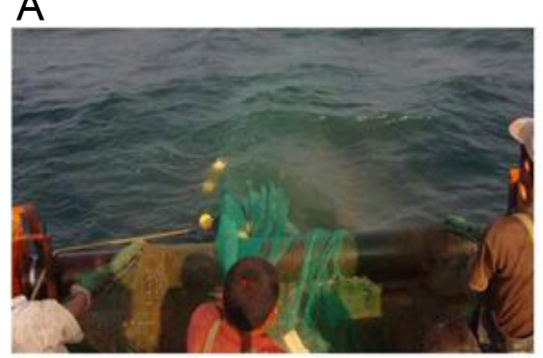

C

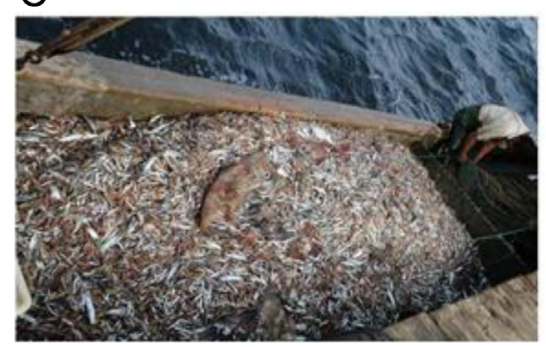

B

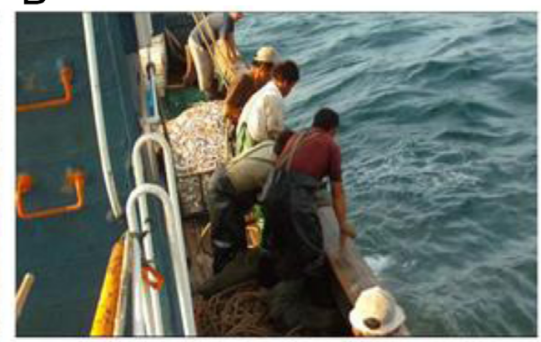

$\mathrm{D}$

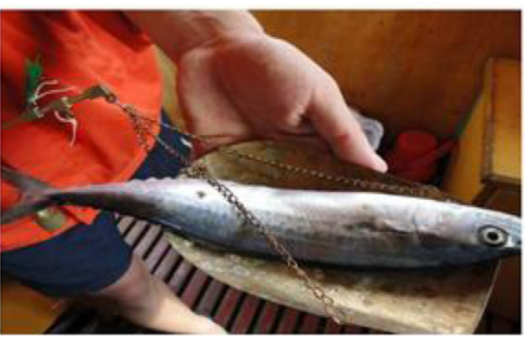

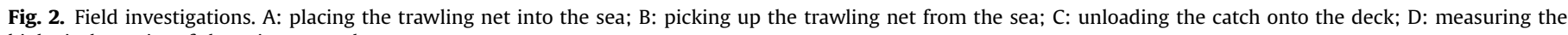
biological metrics of the primary catch.

Zhaoyuan, and Zhifu, along with the Yantai Economic Development and the High-tech zones (Fig. 1).

\subsection{The survey}

Generally, the annual stocking program started in May in the Yantai region. Cultured juveniles were released to the wild, particularly in estuaries. The subsequent harvest began in September after a period with a ban on fishing. Two surveys were conducted to obtain data on fishing related to the stocking program in August of both 2010 and 2011. For each survey, a boat named Luchangyu4193 was hired from the local fisherman with a staff of two who were assisted by three students. Each survey trip lasted between 6 and 9 days depending on the weather conditions. The trawl net was the primary piece of equipment used for the surveys and biological metrics; the lengths and weights were measured for the larger organisms captured (Fig. 2).

\subsection{Data sources}

Both historical statistical data and fishing logs were reviewed to obtain both pre- and post-oil spill data related to the production of the mariculture activities and the local fishery. In particular, fishing vessels provided logs with a record of the fishing activities of vessels during the production process. These logs provided an important reference to obtain fishery information, including time of operation, location, sea conditions, fishing production and other information [26]. Regarding the fishing related to stocking program, production data and market price data were obtained from both field surveys and historical statistics. The survey data were used to complement data from historical literature.

\subsection{Data analysis}

The economic values of mariculture and fisheries were calculated using Eqs (1) and (2):

$$
\begin{aligned}
& L A_{\text {Year }}=\sum_{j=1}^{m} \sum_{i=1}^{n}\left(Q_{i j}^{\text {Year }} P_{i}\right) \\
& L S_{\text {Year }}=\sum_{i=1}^{n} Y_{i}^{\text {Year }} P_{i}
\end{aligned}
$$

where $L A_{\text {Year }}$ and $L S_{\text {Year }}$ indicated the economic value of mariculture and fisheries related to a stocking program for a specific year, respectively; $P_{i}$ denoted the market price of the species $i$, and $Q_{i j}^{\text {Year }}$ represented the yield production of species $i$ for the mariculture sector at zone $j$ of the Yantai for a particular year; $Y_{i}^{\text {Year }}$ referred to the yield production in tons of the species $i$ in the fishing sector on a particular year.

\section{Results}

\subsection{Losses of production in the mariculture sector}

Histograms show the production and yield of the mariculture in Yantai between 2008 and 2013 (Fig. 3a). The total production was always over 0.8 million of tons for 2008, 2009 and 2010. Clearly, total production gradually increased from 2008 to 2010 because of the improvement in mariculture technology as well as the training of qualified personnel $[27,28]$. However, the production and yield decreased to 0.79 million of tons only during 2011. This loss was attributed to the effects of the oil spill during June 2011, which was immediately before the beginning of the harvest season for mariculture. The local mariculture was considered generally to have recovered from the effects of the oil spill in 2012 with a record of 1.12 million of tons of production. In 2013, total production continued to increase to 1.17 million of tons, and reached to the maximal output of the last six years. Furthermore, the increased production for 2012 can be explained by the dispersal of the spilled oil and the recovery of the maricultural environment after the oil spill; in additional, the environmental recovery contributed to the recent expansion of mariculture in the area. Only 99,612 ha of coastal area were used for mariculture in 2008 and this expanded to 150,000 ha in 2012 (Fig. 3b).

The rich biodiversity of the Yantai meant that statistically reliable data were only available for the species with high commercial value [29]. Statistical data were collected annually by the local fishery agency in December of each year. Major species with high commercial value including fish, crustaceans, algae, shellfish and other species in the mariculture sector of Yantai were investigated in this study including fish, prawn, crab, oyster, abalone, mussels, scallop, clams, sinonovacula, algae, sea cucumbers, and sea urchins [30]. 
a

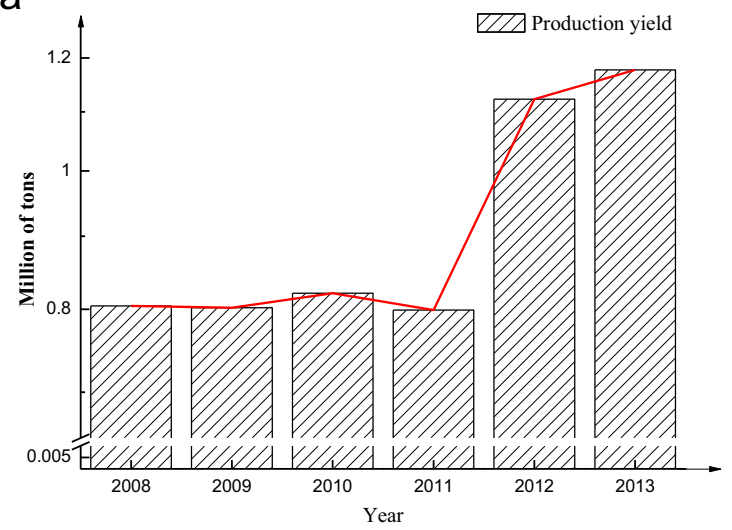

b

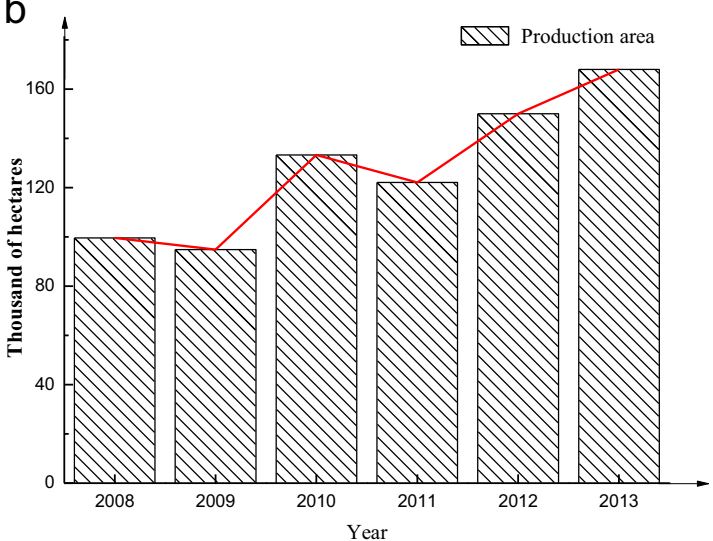

Fig. 3. Historical statistics for mariculture in the Yantai coastal area. A: Yield production data from 2008 to 2013 ; b: production area from 2008 to 2013.

The Penglai 19-3 oil spill occurred in June, 2011. Therefore, the year 2010 was used as the reference year for mariculture production. To estimate the effects of oil pollution on local mariculture, three criteria were examined for both 2010 and 2011 including production yield (tons), cultivation area (ha) and their ratio (Table 1; negative effects are shown in red), which indicated that local mariculture had suffered a loss of production as a result of the oil spill. Fig. 4 shows all species except fish that were more or less affected by the oil spill, as discussed below.

Regarding the production yield, scallops and algae (i.e., seaweed) were the two species most affected by the oil spill with a reduction in catch of 56,694 $\mathrm{t}$ and $13,382 \mathrm{t}$, respectively. A total reduction of yield resulting from the oil pollution for the Yantai mariculture was as high as 63,044 t. Compared with 2010, the area used for the cultivation of each species in 2011 also varied. The area used for the cultivation of three species, prawn, scallop and sea cucumber, declined, while the area used for the cultivation of other species including crab, oyster, abalone, mussel, clam, sinonovacula, algae, sea urchin and fish have increased. Among these others, the sea cucumber experienced to the most significant change, with area of cultivation decreasing from 33,720 ha to 16,183 ha representing a 52\% reduction. This large amount of change could be attributed to the fact that local experienced farmers had abandoned a vast area of cultivation used for sea cucumber in 2011, because the coastal water had been degraded by oil spill; sea cucumber always requires a higher quality of seawater than do other species [31]. The ratio between the production yield and the cultivation area represents the productivity for any particular species. Obviously, 2011 was less productive than 2010 in all species except fish and sea cucumber.

\subsection{Economic losses of production in the mariculture sector}

The market price in 2011 for each individual species was used to estimate the economic loss of mariculture caused by this oil spill (Table 2). The sum of economic loss for those species was up to CNY1239.50 million.

\subsection{Damage to the fishery that is related to the stocking program}

P. chinensis, $P$. trituberculatus, and $R$. esculentum were the three main species cultivated in the stocking program (Table 3). Juveniles of these three species were released annually into the Bohai Sea between May and June. Generally, suitable river inlets, where plentiful food, fewer natural enemies and better environmental conditions that were beneficial to the growth of juveniles have

Table 1

Mariculture yield and area in the Yantai between 2010 and 2011.

\begin{tabular}{|c|c|c|c|c|c|c|c|c|c|}
\hline & \multicolumn{3}{|c|}{ Reference period (2010) } & \multicolumn{3}{|c|}{ After PL situation (2011) } & \multicolumn{3}{|l|}{ Difference } \\
\hline & Ton & Hectare & Ratio & Ton & Hectare & Ratio & Ton & Hectare & Ratio \\
\hline Crustacean & 3737 & 1777 & 2.10 & 2484 & 1512 & 1.64 & -1253 & -265 & -0.46 \\
\hline Prawn & 2301 & 1429 & 1.61 & 1115 & 1042 & 1.07 & -1186 & -387 & -0.54 \\
\hline Crab & 1436 & 348 & 4.13 & 1369 & 470 & 2.91 & -67 & 122 & -1.22 \\
\hline Shellfish & 689,944 & 87,893 & 7.85 & 643,620 & 91,208 & 7.06 & $-46,324$ & 3315 & -13.97 \\
\hline Oyster & 81,702 & 2790 & 29.28 & 86,169 & 4566 & 19 & 4467 & 1776 & -10.28 \\
\hline Abalone & 1456 & 3350 & 0.43 & 1414 & 4695 & 0.30 & -42 & 1345 & -0.13 \\
\hline Mussel & 114,603 & 3243 & 35.34 & 119,814 & 3881 & 30.87 & 5211 & 638 & -4.47 \\
\hline Scallop & 419,473 & 73,010 & 5.75 & 362,779 & 72,110 & 5.03 & $-56,694$ & -900 & -0.72 \\
\hline Clam & 69,931 & 4370 & 16.00 & 70,806 & 4750 & 14.91 & 875 & 380 & -1.09 \\
\hline Sinonovacula & 2779 & 1130 & 2.46 & 2638 & 1206 & 2.19 & -141 & 76 & -0.27 \\
\hline Algae & 77,636 & 4862 & 15.97 & 64,254 & 5200 & 12.36 & $-13,382$ & 338 & -3.61 \\
\hline Others & 24,225 & 37,387 & 0.65 & 22,140 & 20,850 & 1.06 & -2085 & $-16,537$ & 0.13 \\
\hline Sea cucumber & 22,925 & 33,720 & 0.68 & 20,680 & 16,183 & 1.28 & -2245 & $-17,537$ & 0.60 \\
\hline Sea urchin & 1300 & 3667 & 0.35 & 1460 & 4667 & 0.31 & 160 & 1000 & -0.04 \\
\hline Total & 795,542 & 131,919 & 26.57 & 732,498 & 118,770 & 22.12 & $-63,044$ & $-13,149$ & -17.92 \\
\hline Fish & 25,385 & 1345 & 18.87 & 66524 & 3284 & 20.26 & 41,139 & 1939 & 1.39 \\
\hline
\end{tabular}

Note: modified based on valuation report for 2011 Yantai mariculture sector [30]. 


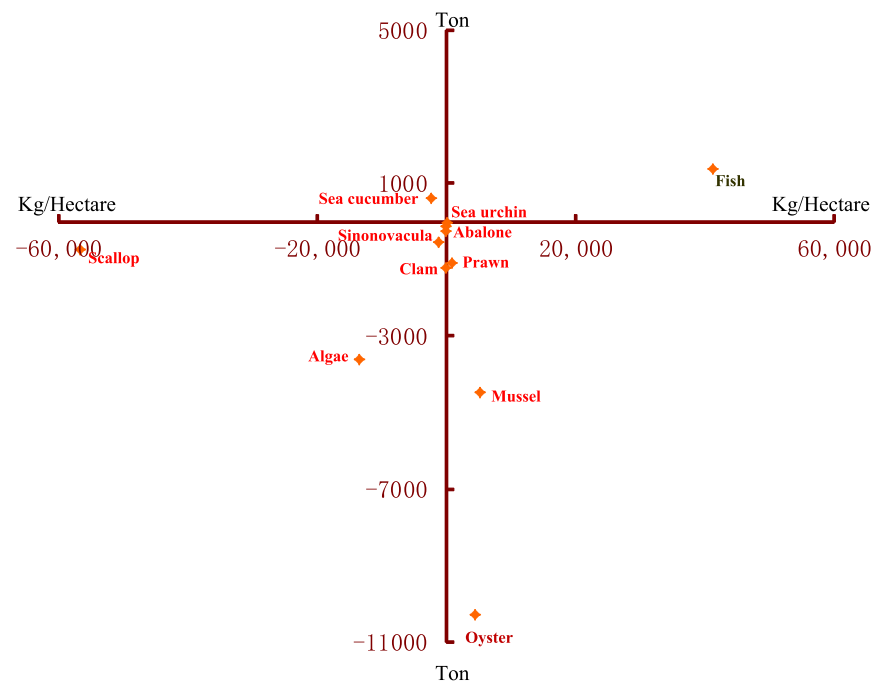

Fig. 4. Changes of total production yield and rate of productivity between 2010 and 2011 for all commercial species. Affected species were marked in red. (For interpretation of the references to color in this figure legend, the reader is referred to the web version of this article.)

been selected as release sites [32,33]. An annual fishing moratorium/ban often lasts three months from the 1 June to the 31 August in the Bohai Sea [34]. Field investigations were conducted using a local fisherman's boat as described above.

As was done for the analysis of mariculture, the year 2010 was also used as a reference year for the stocking program and related species. All three stocked species were affected by the oil spill to varying degrees, based on two years of data (Table 3). Among them, R. esculentum suffered the most with a total loss of $251 \mathrm{t}$ in production weight. Compared with $R$. esculentum, both $P$. chinensis and $P$. trituberculatus were less affected, based on their individual niches as discussed below.

To estimate the economic loss derived from the fishing sector related to the stocking program, both the market price and the cost of fishing in 2010 were expected to remain at the 2011 level. The direct losses in terms of income from sale of $R$. esculentum, $P$. chinensis and P. trituberculatus were CNY3.05 million, CNY12.88 million and CNY0.92 million, respectively. Hence, the economic loss totaled CNY16.85 million for this fishing sector because of the oil spill (Table 3 ).
Table 3

The loss to the stocking program in the fisheries sector.

\begin{tabular}{lrrrrr}
\hline & Year & $\begin{array}{l}\text { Yield } \\
\text { (Ton) }\end{array}$ & $\begin{array}{l}\text { Output va- } \\
\text { lue (Million) }\end{array}$ & $\begin{array}{l}\text { Cost } \\
\text { (Million) }\end{array}$ & $\begin{array}{l}\text { Profit } \\
\text { (Million) }\end{array}$ \\
\hline Penaeus chinensis & 2010 & 821 & 94.21 & 40.48 & 53.73 \\
& 2011 & 732 & 84.00 & 33.32 & 50.68 \\
Portunus & 2010 & 4259 & 153.61 & 53.58 & 100.03 \\
trituberculatus & 2011 & 4193 & 151.23 & 64.08 & 87.15 \\
Rhopilema & 2010 & 1216 & 15.41 & 6.67 & 8.74 \\
esculentum & 2011 & 965 & 12.23 & 4.41 & 7.82 \\
Total & 2010 & 6296 & 263.23 & 100.73 & 162.50 \\
& 2011 & 5890 & 247.46 & 101.81 & 145.65 \\
\hline
\end{tabular}

Note: data gathered from Shandong Hydrobios Resources Conservation and Management Center (the output value was calculated based on the 2011 market price as the reference).

\section{Discussions}

The overall estimated losses reached CNY1256.35 million, of $0.07 \%$ of the Yantai region's GDP in 2011. Mariculture suffered the most significant losses (CNY1239.50 million) which were nearly 74 times as high as the losses in fisheries related to the stocking program (CNY16.85 million). However, the economic losses in the fishery sector were probably underestimated. Note that $P$. chinensis, $P$. trituberculatus, and $R$. esculentum were three major species used in the stocking program. Losses for some other species related to the program were not counted, because of the smaller quantities involved. Nevertheless, larvae were unevenly distributed in the entire Bohai Sea after their discharge from the estuaries. Therefore, the products from those sources may be loaded in other ports away from the coasts of the Yantai region, and so were not counted. Statistical data were collected only for the Yantai coastal areas. However, these figures can indicate the magnitude of the effects on the Yantai fisheries caused by this oil spill.

All species but fish in the mariculture sector were affected by the PL19-3 oil spill. The reason for this was not completely clear, but some explanations are listed below. First, oil released from the PL19-3 spill was mixed with mineral oil-based drilling mud, which was less toxic than crude oil. Second, swimming gives fish the ability to avoid pollution through rapid movement. Lateolabrax

Table 2

Production value in the mariculture sector before and after the PL19-3 oil spill (CNY in million), negative effects are shown in red.

\begin{tabular}{|c|c|c|c|c|c|c|c|}
\hline & \multirow[t]{2}{*}{ Price (Yuan/kg) } & \multicolumn{2}{|c|}{ Reference period (2010) } & \multicolumn{2}{|c|}{ After PL situation (2011) } & \multicolumn{2}{|l|}{ Difference } \\
\hline & & Value & Value/Hectare & Value & Value/Hectare & Value & Value/Hectare \\
\hline Crustacean & 125.42 & 468.68 & 0.264 & 274.23 & 0.181 & -194.45 & -0.082 \\
\hline Prawn & 160.00 & 368.16 & 0.258 & 178.40 & 0.171 & -189.76 & -0.086 \\
\hline Crab & 70.00 & 100.52 & 0.289 & 95.83 & 0.204 & -4.69 & -0.085 \\
\hline Shellfish & 9.84 & 6792.29 & 0.077 & 6193.69 & 0.068 & -598.61 & -0.009 \\
\hline Oyster & 4.00 & 326.81 & 0.117 & 344.68 & 0.076 & 17.87 & -0.041 \\
\hline Abalone & 400.00 & 582.40 & 0.172 & 565.60 & 0.120 & -16.80 & -0.052 \\
\hline Mussel & 4.00 & 458.41 & 0.141 & 479.26 & 0.123 & 20.84 & -0.018 \\
\hline Scallop & 11.00 & 4614.20 & 0.063 & 3990.57 & 0.055 & -623.63 & -0.008 \\
\hline Clam & 10.00 & 699.31 & 0.160 & 708.06 & 0.149 & 8.75 & -0.011 \\
\hline Sinonovacula & 40.00 & 111.16 & 0.098 & 105.52 & 0.088 & -5.64 & -0.011 \\
\hline Algae & 5.20 & 403.71 & 0.083 & 334.12 & 0.064 & -69.59 & -0.019 \\
\hline Others & 162.49 & 3936.25 & 0.105 & 3559.40 & 0.170 & -376.85 & 0.065 \\
\hline Sea cucumber & 170.00 & 3897.25 & 0.116 & 3515.60 & 0.218 & -381.65 & 0.102 \\
\hline Sea urchin & 30.00 & 39.00 & 0.011 & 43.80 & 0.009 & 4.80 & -0.001 \\
\hline Total & & $11,600.93$ & 0.53 & $10,361.44$ & 0.48 & -1239.50 & -0.05 \\
\hline
\end{tabular}

Note: modified based on valuation report for 2011 Yantai mariculture sector [30]. The value was calculated based on the 2011 market price as the reference. 
japonicus and Sebastes schlegeli were the main fish used in mariculture. Swimming allowed these species to avoid pollution by fleeing the scene at a maximum sustained speed of greater than $36.9 \mathrm{~cm} / \mathrm{s}$ [35]. Third, the species all move along the seabed [36]. Their larger and stronger bodies also play an important role in allowing them to resist the effects of poisonous substances than the other species.

Compared with $P$. chinensis and $P$. trituberculatus, the production for $R$. esculentum fell sharply in the fishery related to stocking program. In addition, when $R$. esculentum swims in the seawater it has a relatively weak ability to swim and prefers to move vertically in the water [37]. Nevertheless, P. chinensis and P. trituberculatus have continuous coverings on their bodies that help them avoid being exposed directly to pollution. They both crawl on the seabed and occasionally swim in the water [38,39]. Oil tends to float on the surface of the water and does less harm to these particular crustaceans than it does to R. esculentum. Additional tests will be needed to allow us to draw further conclusions.

The PL19-3 oil spill had also an effect on other surrounding coastal areas including shorelines of Hebei and Liaoning provinces as mentioned in the introduction, although estimates of economic impacts in those areas were not made in this study. The losses to their individual fisheries caused by this spill would be expected to be as high as that in the Yantai area. If the economic effects on the Hebei and Liaoning fisheries could be included, the total damages could be double or triple those in Yantai (CNY1256.35 million). However, the final compensation provided for damage to the fisheries by the PL19-3 was only CNY1000 million [2]. This level of compensation even could not cover the economic losses in the Yantai fishery along based on our conservative estimates.

\section{Conclusions}

Despite the fact that secondary data combined with occasional field investigations were used in the present economic assessment, the magnitude of the economic effects caused by the PL19-3 oil spill were considerable. A conservative estimate of short-term economic losses in the Yantai fisheries stood at CNY1256.35 million during 2011; this excluded the value of environmental losses and other economic sectors affected by the spill such as tourism in the Yantai area. If the affected coasts in the Hebei and Liaoning provinces had been considered in detail, the total cost would be rather significant. However, the compensation for fishery losses was limited to CNY1000 million, which was agreed upon by the oil companies, the Ministry of Agriculture and the local governments of the provinces suffering from the oil spills. Obviously, this quantity was much lower than the actual cost of fishery damages and it was even not able to cover the reasonable losses in the Yantai fisheries (i.e., CNY1256.35 million).

Finally, a more complete estimation of the total cost of the Penglai 19-3 oil spill should be made in the future to provide a comprehensive view of the spill's effects. Following Liu and Wirtz [21], the total cost should consist of five categories including economic losses, environmental damages, clean-up costs, research costs, and other expenditures [21]. The losses in fishery sectors are only one sub-category of economic losses in the context of the total cost. Nevertheless, this paper provides an initial effort to the assess economic losses in terms of damage to fisheries by the oil spill based on real data including official and unofficial statistical data along with data from field investigations.

Additionally, the evaluations of economic damage provided here may be used as an important decision making tool when estimating the optimal level of protection that should be employed to protect the marine environment and related economic resources in order to avoid similar damage by this type of accident in the future.

\section{Acknowledgments}

This study was made possible thanks to the jointly financial support from the Key Research Program of the Chinese Academy of Sciences, Grant no. KZZD-EW-14, the National Program on Key Basic Research Project of China (973 Program, 2015CB453300) and the National Natural Science Foundation of China with a reference of 41371483.

\section{References}

[1] E.R. Gundlach, M.O. Hayes, Vulnerability of coastal environments to oil spill impacts, Mar. Technol. Soc. J. 12 (1978) 18-27.

[2] COPC. 〈http://www.conocophillips.com.cn/EN/sustainable-development/re sponse-to-pl19-3-incidents/Pages/default.aspx $\rangle$.

[3] Science Consortium for Ocean Replenishment (SCORE). 〈http://www.stock enhancement.org $\rangle$.

[4] H.L. Blankenship, M.L. Kenneth, A responsible apporach to marine stock enhancement, Am. Fish. Soc. Symp. 15 (1995) 167-175.

[5] T. Wada, K. Kamiyama, S. Shimamura, T. Mizuno, Y. Nemoto, Effectiveness of stock enhancement of a rare species, spotted halibut Verasper variegatus, in Fukushima, Jpn. Aquac. 364-365 (2012) 230-239.

[6] A.F. Born, A.J. Immink, D.M. Bartley, Marine and coastal stocking: global status and information needs, in: D.M. Bartley, K.M. Leber (Eds.), FAO Fisheries Technical Paper 429, Marine ranching, FAO, Rome, 2004, pp. 1-12.

[7] K.M. Leber, Summary of case studies of the effectiveness of stocking aquacultured fishes and invertebrates to replenish and enhance coastal fisheries, in: D.M. Bartley, K.M. Leber (Eds.), FAO Fisheries Technical Paper 429, Marine ranching, FAO, Rome, 2004, pp. 203-213.

[8] IC. Liao, M.S. Su, E.M. Leaño, Status of research in stock enhancement and sea ranching, Rev. Fish Biol. Fish. 13 (2003) 151-163.

[9] Yan Zhao Du Shi Bao (YZDSB). 〈http://epaper.yzdsb.com.cn/201301/26/218256. html>.

[10] State Oceanic Administration People's Republic Of China (SOAPROC). 〈http:/ www.soa.gov.cn/xw/ldhd/wf/201211/t20121107 4908.html $>$.

[11] X.W. Wang, C.H. Li, N.N. Shen, Effect of oil pollution on marine organism, South China Fish. Sci. 2 (2006) 76-80.

[12] WIKI. 〈http://en.wikipedia.org/wiki/2011_Bohai_Bay_oil_spill〉.

[13] M. Alló, M.L. Loureiro, Estimating a meta-damage regression model for large accidental oil spills, Ecol. Econ. 86 (2013) 167-175.

[14] D. Kim, G. Yang, S. Min, C. Koh, Social and ecological impacts of the Hebei Spirit oil spill on the west coast of Korea: Implications for compensation and recovery, Ocean Coast. Manag. 102 (2014) 533-544.

[15] F. Bonnieux, Evaluation économique du préjudice ecologique causé par le naufrage de l'Erika, Rapport Confidentiel, 2006.

[16] IOPC Funds, Incidents Involving the IOPC Funds 2012, International Oil Pollution Compensation Funds, London, United Kingdom, 2013.

[17] M.F. Kirby, R.J. Law, Accidental spills at sea-Risk, impact, mitigation and the need for co-ordinated post-incident monitoring, Mar. Pollut. Bull. 60 (2010) 797-803.

[18] H.R. de la, M. Lastra, J. Junoy, C. Castellanos, J.M. Viéitez, Biological impacts of oil pollution and cleaning in the intertidal zone of exposed sandy beaches: preliminary study of the "Prestige" oil spill, Estuar. Coast. Shelf Sci. 65 (2005) 19-29.

[19] C. Morales-Caselles, J. Kalman, I. Riba, T.A. DelValls, Comparing sediment quality in Spanish littoral areas affected by acute (Prestige, 2002) and chronic (Bay of Algeciras) oil spills, Environ. Pollut. 146 (2007) 233-240.

[20] F. Sánchez, F. Velasco, J.E. Cartes, I. Olaso, I. Preciado, E. Fanelli, A. Serrano, ]. L. Gutierrez-Zabala, Monitoring the Prestige oil spill impacts on some key species of the Northern Iberian shelf, Mar. Pollut. Bull. 53 (2006) 332-349.

[21] X. Liu, K.W. Wirtz, Total oil spill costs and compensations, Marit. Policy Manag. 33 (2005) 49-60.

[22] M.L. Loureiro, A. Ribas, E. Lopez, E. Ojea, Estimated costs and admissible claims linked to the Prestige oil spill, Ecol. Econ. 59 (2006) 48-63.

[23] MLTM, The White Paper on Hebei Spirit oil Spill: Compensation Section (part 2) for Damages from the Hebei Spirit oil Spill, Ministry of Land, Transport and Maritime Affairs Report, 2012.

[24] Y.P. Wen, C.W. Wu, The direct economic damage assessment caused by the Dalian Xingang “7.16 oil spill accident”, Chin. Fish. Econ. 4 (2013) 91-96.

[25] L.D. He, Smelly oil on the beach, XinMin Weekly (2011) 30-35.

[26] K.J. Wu, G.M. Hu, S. Zhang, X.X. Fu, Development and application of fishing log management system, Mar. Fish. 205 (2006) 152-157.

[27] S.L. Dong, The development history, principle and classification of China's integrated aquaculture, J. Fish. Sci. China 5 (2011) 1202-1209.

[28] J. Gu, H. Xu, G. Wang, The research progress of aquaculture equipment and engineering (2009), Hebei Fish. 5 (2011) 1202-1209 (In Chinese).

[29] M.C. García Negro, S. Villasante, A. Carballo Penela, G. Rodríguez Rodríguez, Estimating the economic impact of the Prestige oil spill on the Death Coast (NW Spain) fisheries, Mar. Policy 33 (2009) 8-23.

[30] Valuation report for 2011 Yantai mariculture sector, 2011.

[31] S. Chi, Y. Zeng, Z.J. Zhao, L.B. Cui, Variation of Water Quality in Culture Ponds for Apostichopus Japonicus, J. Univ. Jinan 27 (2013) 239-244. 
[32] X.W. Pan, L.L. Yang, W.W. Ji, Z.L. Liu, The research progress of the stock enhancement technology, Jiangsu Agric. Sci. 4 (2010) 236-240.

[33] R.Y. Chen, B. Lou, W. Zhan, D.D. Xu, G.M. Mao, H.L. Shi, The discussion of technology in the stock enhancement program, Hebei Fish. 5 (2014) 50-54.

[34] Y.M. Chen, T. Bao, The reasearch of Chinese system of summer fishing moratorium, Hebei Fish. 9 (2010) 46-50.

[35] A.G. Jing, X.M. Zhang, W.T. Li, A Preliminary Experiment on Swimming Ability of Lateolabrax maculatus and Sebastes schlegeli, Period. Ocean Univ. China 35 (6) (2005) 973-976.
[36] D.G. Chen, Fishery Ecology in the Bohai and the Yellow Sea, Ocean Press, Beijing, 1991.

[37] Z.F. Yin, N. Li, Introduction of several Rhopilema ecculentum along the Shandong coast, Chin. J. Zool. 1 (1977) 40-42.

[38] A.L. Wang, X.Q. Mu, S.M. Zhou, Behavioral observation of Penaeus chinensis, Mar. Sci. 4 (1993) 16-18.

[39] G.B. Cheng, H.L. Sheng, B. Lou, G.M. Mao, W. Zhan, D.D. Xu, B.G. Xue, Biological characteristics and artificial propagation culture techniques for Portunus trituberculatus, Hebei Fish. 4 (2012) 59-61. 